\title{
Mechanical ventilation may increase susceptibility to the development of bacteremia
}

\author{
Chang-Yi Lin, MD; Haibo Zhang, MD, PhD; Kuo-Chen Cheng, MD; Arthur S. Slutsky, MD
}

Objective: We examined the hypothesis that mechanical ventilation with a potentially injurious strategy would predispose animals to the detrimental effects of subsequent instillation of bacteria.

Design: Interventional animal study.

Setting: A university hospital research laboratory.

Subjects: Fifty Sprague-Dawley male rats.

Interventions: Rats were anesthetized and randomized to receive a protective (tidal volume $7 \mathrm{~mL} / \mathrm{kg}$, positive end-expiratory pressure $5 \mathrm{~cm} \mathrm{H}_{2} \mathrm{O}, \mathrm{n}=25$ ) or an injurious ventilatory strategy (tidal volume $21 \mathrm{~mL} / \mathrm{kg}$, zero positive end-expiratory pressure, $\mathrm{n}$ $=25$ ). Hemodynamics were similar during the $1-\mathrm{hr}$ ventilation period in the two groups. Animals were then disconnected from the ventilator and Pseudomonas aeruginosa was instilled intratracheally before extubation. Thereafter, animals breathed spontaneously; mortality rate was assessed up to $\mathbf{4 8} \mathrm{hrs}$, at which time the animals were killed.

Measurements and Main Results: The 48-hr mortality rate was
$28 \%$ in the protective group and $40 \%$ in the injurious group ( $p=$ not significant). A positive bacterial culture from the lung was obtained in $56 \%$ of the surviving rats in the low tidal volume group and $67 \%$ in the high tidal volume group $(p=.059)$. A positive blood bacterial culture was found in $11 \%$ of the low tidal volume group and $33 \%$ in the high tidal volume group $(p<.05)$. The absolute bacterial count in the blood was lower in the low tidal volume group compared with the high tidal volume group ( $p<$ .05). Concentrations of blood tumor necrosis factor- $\alpha$ and macrophage inflammatory protein-2, and lung macrophage inflammatory protein-2 at $\mathbf{4 8}$ hrs were significantly higher in the low tidal volume group than in the high tidal volume group.

Conclusions: An injurious ventilatory strategy predisposes animals to subsequent bacteremia associated with an impaired host defense reflected by cytokine response. (Crit Care Med 2003; 31:1429-1434)

KEY WoRDS: cytokines; tumor necrosis factor; ventilators; pneumonia; lung
$\mathrm{V}$ entilator-associated pneumonia and sepsis are major causes of death in hospitalacquired infection $(1,2)$. A high frequency of pneumonia and bacteremia in patients who have been mechanically ventilated for prolonged periods of time may be caused by multiple factors including an impaired host defense system. Several animal studies have demonstrated that mechanical ventilation with high tidal volume (ป்) and zero positive end-expiratory pressure (PEEP) after in-

From the Chest Section, Department of Medicine, Mackay Memorial Hospital, Taiwan (C-YL); Departments of Anaesthesia and Critical Care Medicine, St Michael's Hospital, University of Toronto, Canada (HZ, ASS); and the Department of Critical Care Medicine, Tainan Chi Mei Fundation Hospital, Taiwan (K-CC).

Supported, in part, by grants from Canadian Institutes of Health Research (MOP-44093 to Dr. Zhang, MA-8558 to Dr. Slutsky).

Address requests for reprints to: Arthur S. Slutsky, MD, St. Michael's Hospital, Room 4042, Queen Wing, 30 Bond Street, Toronto, Ontario, Canada M5B 1W8. E-mail: arthur.slutsky@utoronto.ca

Copyright (C) 2003 by Lippincott Williams \& Wilkins

DOI: 10.1097/01.CCM.0000063449.58029.81 tratracheal instillation of bacteria causes an increase in bacteremia, suggesting that mechanical ventilation can promote bacterial translocation from the lung into the systemic circulation $(3,4)$. One factor that could lead to increased susceptibility to pneumonia and/or bacteremia is the damage to the lung caused by mechanical ventilation-so-called ventilator-induced lung injury. For example, epithelial injury secondary to ventilator-induced lung injury has been described by several groups (5-7), and epithelial injury has been shown to increase susceptibility to bacterial infection.

Mechanical ventilation is often begun in many patients before there is overt evidence of pneumonia and could have an impact on development of infectious complications by affecting several host defense mechanisms. Injurious ventilatory strategies can lead to the release of inflammatory mediators including cytokines. In previous studies, we and others have shown that mechanical ventilation using high VंT and zero PEEP resulted in release of tumor necrosis factor (TNF)- $\alpha$, a pivotal proinflammatory cytokine, and macrophage inflammatory protein (MIP)-2, a member of the CXC group of chemokines in the lung (8) and systemic circulation $(9,10)$. This has led to the concept that mechanical ventilation may affect not only the lung but also cause a systemic inflammatory response $(9,10)$. Although the exact role of the cytokine release caused by mechanical ventilation is not yet clear, it has been suggested that early cytokine production is part of a generalized host response, but that excessive release of cytokines may in turn impact on host defense by augmenting inflammation and lead to extensive injury (11, 12).

The importance of ventilatory strategies on outcome of patients with acute respiratory distress syndrome has been highlighted by the results of the National Institutes of Health-sponsored acute respiratory distress syndrome network trial that observed a $22 \%$ decrease in mortality using a low Vं ventilatory strategy as compared with high Vंт (13). Given these experimental and clinical observations, we wondered whether injurious strategies of mechanical ventilation could have 
an impact on host defense when given for a period prior to the introduction of bacteria in the lung. This would have implications with respect to preventing excessive systemic inflammatory response, distal organ injury, and perhaps death induced by mechanical ventilation. To address this question, we used a rat model of mechanical ventilation followed by installation of bacteria into the lung. We found that ventilation with high VT $(21 \mathrm{~mL} / \mathrm{kg})$ and zero PEEP increased bacteremia and was associated with a decreased concentration of TNF- $\alpha$ and MIP-2, as compared with a group ventilated with low VंT $(7 \mathrm{~mL} / \mathrm{kg})$ and PEEP (5 $\mathrm{cm} \mathrm{H}_{2} \mathrm{O}$ ).

\section{MATERIALS AND METHODS}

\section{Bacterial Preparation}

Pseudomonas aeruginosa (ATCC 33358, Rockville, MD) were thawed and cultured overnight (14 to $16 \mathrm{hrs)} \mathrm{in} \mathrm{full-strength} \mathrm{tryp-}$ ticase soy broth (Becton Dickinson, Cockeysville, MD) at $37^{\circ} \mathrm{C}$ in a shaking water bath to obtain stationary-phase organisms. A 2-mL aliquot of this overnight culture was transferred into $50 \mathrm{~mL}$ of full strength trypticase soy broth and incubated at $37^{\circ} \mathrm{C}$ for 2 hrs to obtain mid-logarithmic phase organisms. A portion $(25 \mathrm{~mL})$ of the culture was centrifuged at $800 \times g, 4^{\circ} \mathrm{C}$ for 10 mins. After the supernatant was discarded, the bacterial pellet was resuspended in cold, sterile buffer and washed again at $800 \times g$ for 10 mins at $4^{\circ} \mathrm{C}$. The pellet was resuspended in $5 \mathrm{~mL}$ of buffer, and adjusted to a stock concentration of approximately $1 \times 10^{6}$ colony-forming units (CFUs) $/ \mathrm{mL}$ of $P$. aeruginosa in cold sodium phosphate buffer, kept on ice, and mixed (vortex) before use.

\section{Experimental Protocol}

The experimental protocol was approved by the Animal Use Committee of the University of Toronto. Fifty adult Sprague-Dawley male rats (Charles River, St. Constant, Quebec, Canada) were anesthetized with an initial intraperitoneal injection of $70 \mathrm{mg} / \mathrm{kg}$ ketamine and 25 $\mathrm{mg} / \mathrm{kg}$ xylazine. An angiocatheter (Angiocath, 14-gauge, Becton Dickinson Infusion Therapy Systems, Sandy, UT) was inserted into the trachea via the mouth, under laryngoscopic guidance. A second intraperitoneal bolus injection of anesthetic (35 mg/kg ketamine and $12.5 \mathrm{mg} / \mathrm{kg}$ xylazine) was given for maintenance of anesthesia 2 mins after intratracheal intubation. The rats were then mechanically ventilated using a Harvard Rodent Ventilator (683, Harvard Apparatus, South Natick, MA) with room air using a VंT of $7 \mathrm{~mL} / \mathrm{kg}$, PEEP 5 $\mathrm{cm} \mathrm{H}_{2} \mathrm{O}$, and respiratory rate 40 breaths/min for 5 mins. Heart rate and arterial oxygen saturation $\left(\mathrm{SaO}_{2}\right)$ (Pulse oximeter, $8600 \mathrm{~V}$, Nonin Medical, Minneapolis, MN) were monitored.

On each experimental day, two rats were randomized to receive one of two mechanical ventilation strategies both using an $\mathrm{FIO}_{2}=$ 0.4: group 1 (protective) received mechanical ventilation with $\dot{\mathrm{V}} 7 \mathrm{~mL} / \mathrm{kg}$, PEEP $5 \mathrm{~cm} \mathrm{H}_{2} \mathrm{O}$, and a respiratory rate of 40 breaths/min; group 2 (injurious) received VT $21 \mathrm{~mL} / \mathrm{kg}$, zero PEEP, and a respiratory rate of 40 breaths/ min. The pairing of one rat from each group for these studies was done to ensure that the instilled bacterial numbers would be virtually identical between the two groups.

Upon completion of $1 \mathrm{hr}$ of ventilation, 0.3 $\mathrm{mL}$ of $10^{6} \mathrm{CFUs} / \mathrm{mL} P$. aeruginosa was instilled into the trachea of the rats, followed by a recruitment maneuver increasing peak airway pressure to $25 \mathrm{~cm} \mathrm{H}_{2} \mathrm{O}$; the rats were then ventilated with a VT of $10 \mathrm{~mL} / \mathrm{kg}$ and a respiratory rate of 40 breaths/min for 2 mins to maximize distribution of bacteria in the lung. Because no muscle relaxants were used, the rats rapidly (5 to 10 mins) resumed spontaneous breathing after disconnection from the ventilator, before extubation. The rats were then returned to cages with free access to diet and water, and observed for 48 hrs. Animals that survived to 48 hrs were killed under sterile conditions after an overdose of phenobarbital. Arterial blood was collected in heparinized tubes just before kill. The lungs were then excised and the left lung was homogenized for measurement of cytokines and bacterial count; the right lung was fixed with $10 \%$ formaldehyde (BDH, Toronto, ON) for histologic examination.

\section{Measurements}

Hemodynamics. Because we intended to examine the frequency of bacteremia and mortality at 48 hrs, noninvasive hemodynamic monitoring was required. Thus, we only monitored heart rate and $\mathrm{SaO}_{2}$ by using a veterinary pulse co-oximeter (Nonin 8600, Plymouth, MN) during the whole ventilation and weaning period.

By study design, the ventilatory variables were adjusted to obtain similar mean airway pressures. Hence, we did not expect any systematic differences in hemodynamics between the two groups. To ensure that there were not large differences in hemodynamics, in a separate set of experiments, we studied four rats to examine the effect of the two ventilatory strategies on hemodynamics. In these studies, the right carotid artery of each animal was cannulated for measurements of arterial pressure and heart rate (Datascope 2001, Datascope, Paramus, NJ). The rats were then intratracheally intubated via the oral route, and mechanically ventilated with a Harvard Rodent Venti- lator (683, Harvard Apparatus) using $\mathrm{FIO}_{2}=$ 0.4 ; two rats were ventilated with the noninjurious ventilatory strategy and two with the injurious strategy as described above. The animals were then killed.

Ventilatory Variables. $\mathrm{SaO}_{2}$ was monitored with an oximeter (Nonin 8600). Peak airway pressure and mean airway pressure were transduced from the Harvard Rodent Ventilator (Harvard Apparatus) to a calibrated pressure ventilatory monitor (Rodent Ventilator RV4, Enterprises, Toronto, ON) for real-time monitoring.

Bacterial Counts in Blood and Lung Homogenates. Bacterial counts were performed in the rats that survived for 48 hrs. Briefly, $50-\mu \mathrm{L}$ samples of either blood or lung homogenates were separately diluted in $450 \mu \mathrm{L}$ of normal saline. After mixing, $100 \mu \mathrm{L}$ was plated on a trypticase soy broth agar plate and incubated at $37^{\circ} \mathrm{C}$ for $24 \mathrm{hrs}$; the number of CFUs was then counted.

Assays for Cytokines. Blood samples and lung homogenates were centrifuged. The supernatants were used for measurements of cytokines. Commercially available enzymelinked immunosorbent assay kits were used for measurements of rat TNF- $\alpha$ and MIP-2 (Cytoscreen, Immunoassay Kit, BioSource International, Camarillo, CA). The detection limit of these specific kits for rat is $<4 \mathrm{pg} / \mathrm{mL}$ and $<1 \mathrm{pg} / \mathrm{mL}$ for TNF- $\alpha$ and MIP 2 , respectively. The absorbance of each well was read at $450 \mathrm{~nm}$ with an MR 600 microplate reader (Thermonmax-Molecular Devices, Fisher Scientific Instrument, Nepean, ON).

\section{Lung Histology}

The lungs were fixed by immersion in $10 \%$ buffered neutral formalin and were processed using standard histologic techniques. A pathologist read the morphologic slides in a blinded manner.

\section{Statistical Analysis}

The data are expressed as mean $\pm \mathrm{SE}$. Statistical analysis was done with analysis of variance followed by Tukey-Kramer test. Bacterial counts were analyzed using nonparametrics methods followed by Kruskal-Wallis test. A $p$ value $<.05$ was considered as statistically significance.

\section{RESULTS}

The mean body weights were not different in the two groups of rats $(304 \pm$ $6 \mathrm{~g}$ in the protective group vs. $298 \pm 5 \mathrm{~g}$ in the injurious group, $p=\mathrm{NS}$ ). In our pilot study, we used four rats to investigate the mean arterial pressure, heart rate, and mean airway pressure. There were no large differences in mean arterial pressure (120 \pm 7 in protective vs. $140 \pm$ 
$8 \mathrm{~mm} \mathrm{Hg}$ in injurious group at time 0 , and $115 \pm 1$ vs. $130 \pm 10 \mathrm{~mm} \mathrm{Hg}$ at 60 mins of mechanical ventilation, $p=$ not significant for all), heart rate $(254 \pm 21$ vs. $278 \pm 31$ at time $0,229 \pm 29$ vs. 225 \pm 35 at 60 mins, respectively, $p=$ not significant for all), mean airway pressure and $\mathrm{SaO}_{2}$ (Figs. 1 and 2), despite a significant difference in peak airway pressure between the two groups over the period of 1-hr ventilation. Because the heart rate, mean arterial pressure, and mean airway pressure were similar between the two ventilation groups as tested in four animals with a tendency to increase blood pressure in the injurious group, we did not study anymore animals with invasive hemodynamic monitoring.

The inoculated bacterial number was similar in the two groups $(1.84 \pm 0.21 \times$ $10^{5} \mathrm{CFUs} / \mathrm{mL}$ in the protective group vs. $1.96 \pm 0.23 \times 10^{5} \mathrm{CFUs} / \mathrm{mL}$ in the injurious group). The 48-hr mortality rate was $28 \%$ (seven of 25 rats) in the protective ventilatory strategy group and $40 \%$ (ten of 25 rats) in the injurious group ( $p$ $=$ not significant). Table 1 shows the frequency of positive bacterial culture in lung homogenates and blood from the two groups. The rate of positive bacterial cultures in the lung tended to be lower in the protective compared with the injurious group ( $56 \%$ vs. $67 \%, p=.059$ ); positive blood cultures were significantly lower in the protective group than in the injurious group (11\% vs. $33 \%, p<.05)$. The absolute bacterial counts tended to be lower in the lung (approximately three-fold, $p=.067$ ) and were significantly lower in the blood (approximately 60 -fold, $p<.05)$ in the protective ventilatory strategy group than in the injurious group (Fig. 3).

To investigate local and systemic host defense responses reflected by cytokine production, concentrations of TNF- $\alpha$ and MIP-2 in the lung and blood were measured. Lung TNF- $\alpha$ levels were not statistically different in the two groups (Fig. 4 $A$ ). Lung MIP-2 levels were higher in the protective strategy group than in the injurious group (Fig. $4 \mathrm{~B}$ ). Blood concentrations of TNF- $\alpha$ and MIP-2 were both significantly higher in the protective group than in the injurious group (Fig. 4). The cytokine levels did not correlate with positive cultures.

The gross appearance of histology was not significantly different between the two groups of lungs. Three of ten lungs in the low VT ventilation group and eight of ten lungs in the high Vंт group showed

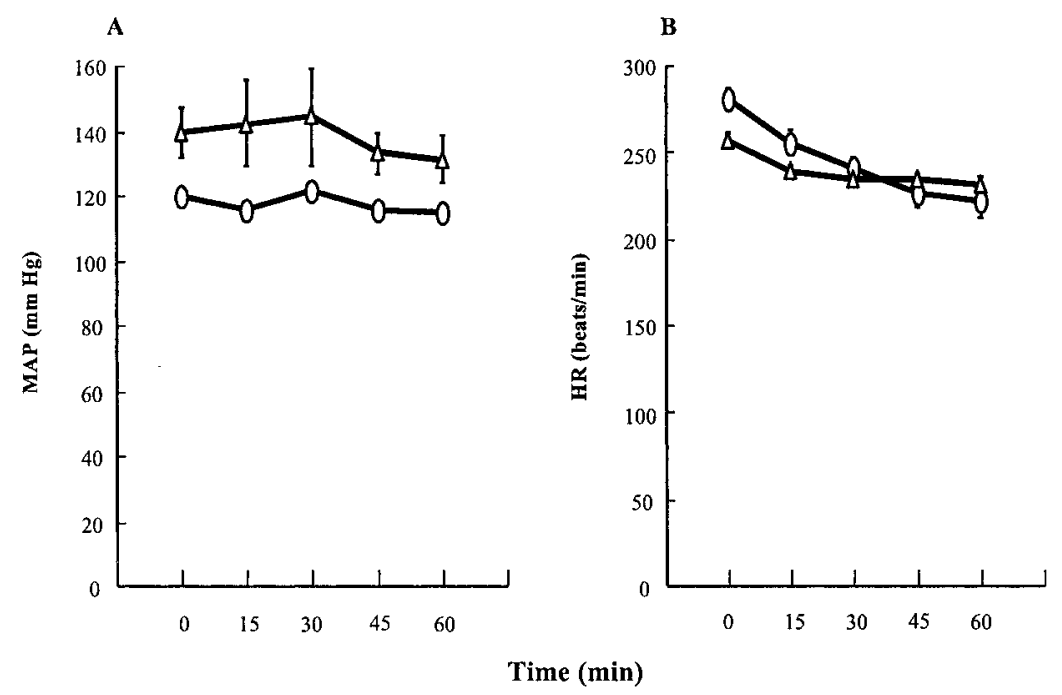

Figure 1. Time course of mean arterial pressure $(M A P)(A)$ and heart rate $(B)$ during mechanical ventilation. Animals were ventilated with either tidal volume $7 \mathrm{~mL} / \mathrm{kg}$ and positive end-expiratory pressure (PEEP) $5 \mathrm{~cm} \mathrm{H} \mathrm{H}_{2} \mathrm{O}$ (circles) or $21 \mathrm{~mL} / \mathrm{kg}$ with zero PEEP (triangles) for $1 \mathrm{hr}$ under $\mathrm{FIO}_{2} 0.4$.
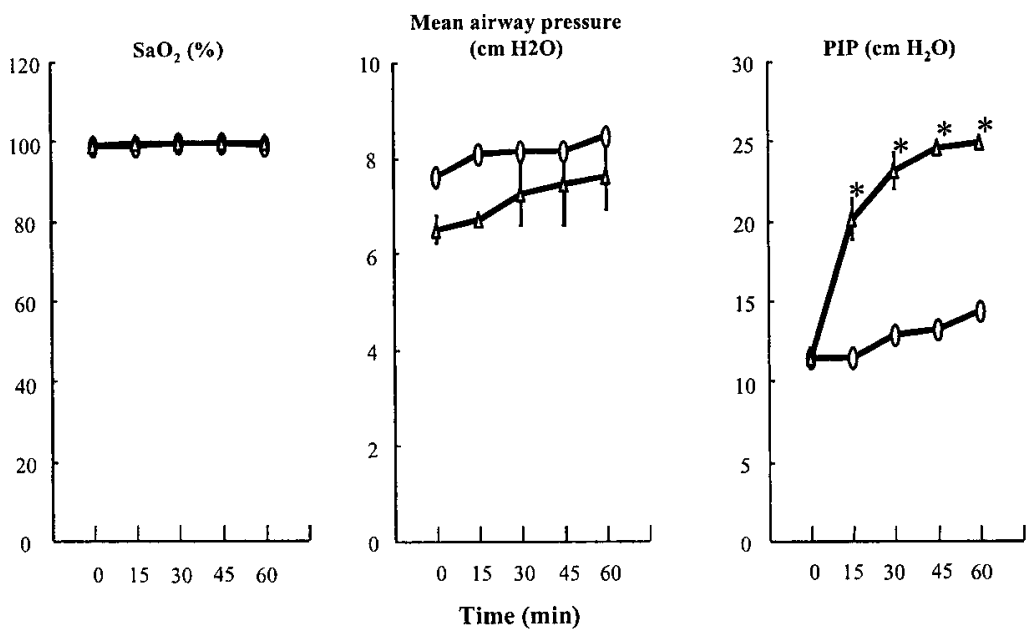

Figure 2. Time course of arterial oxygen saturation $\left(\mathrm{SaO}_{2}\right)$, mean airway pressure, and peak inspiratory pressure $(P I P)$ during mechanical ventilation. Animals were ventilated with either tidal volume (VंT) 7 $\mathrm{mL} / \mathrm{kg}$ and positive end-expiratory pressure (PEEP) $5 \mathrm{~cm} \mathrm{H}_{2} \mathrm{O}$ (circles) or $21 \mathrm{~mL} / \mathrm{kg}$ with zero PEEP (triangles) for $1 \mathrm{hr}$ under $\mathrm{FIO}_{2}$ 0.4. * $p<.05$ vs. low $\mathrm{V}$ T with PEEP group at the given time.

slight epithelial disruption, edema, or neutrophil infiltrations.

\section{DISCUSSION}

\section{A Novel Model of Mechanical Ventilation-Associated Bacteremia}

To address whether mechanical ventilation can increase susceptibility to a subsequent bacterial infection, we used a model of mechanical ventilation, followed by bacterial intratracheal instillation. Our model differs from other animal models described previously in which
Table 1. Positive bacterial culture in lung homogenates and blood

\begin{tabular}{lrr}
\hline & Low Vंт PEEP5 & High Vंт PEEP0 \\
\hline Lung & $10 / 18(56 \%)$ & $10 / 15(67 \%)^{a}$ \\
Blood & $2 / 18(11 \%)$ & $5 / 15(33 \%)^{b}$ \\
\hline
\end{tabular}

VंT, tidal volume; PEEP, positive end-expiratory pressure.

$a_{p}=.059$ high Vंт $21 \mathrm{~mL} / \mathrm{kg}$ vs. low VT $7 \mathrm{~mL} / \mathrm{kg}$ in lung; ${ }^{b} p=.020$ high $\dot{V}$ T vs. low $\dot{V}$ T in blood.

bacteria were injected first, followed by mechanical ventilation $(3,4,14)$. The major finding of the present study is that application of an injurious ventilatory 

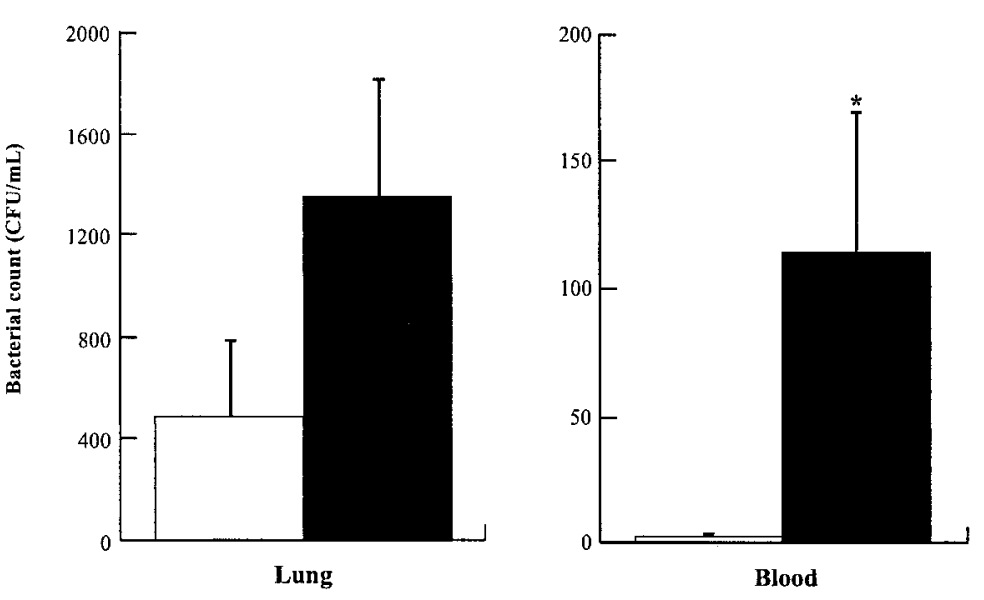

Figure 3. Bacterial count from lung homogenates and blood 48 hrs after Pseudomonas aeruginosa intratracheal inoculation. Animals were ventilated with either tidal volume (V்T) $7 \mathrm{~mL} / \mathrm{kg}$ and positive end-expiratory pressure (PEEP) $5 \mathrm{~cm} \mathrm{H}_{2} \mathrm{O}$ (open bars, $\mathrm{n}=18$ ) or $21 \mathrm{~mL} / \mathrm{kg}$ with zero PEEP (filled bars, $\mathrm{n}=15$ ) under $\mathrm{FIO}_{2} 0.4$ for $1 \mathrm{hr}$ before bacterial challenge. ${ }^{*} p<.05$ vs. low VT with PEEP group in the same specimens. $\mathrm{CFU}=$ colony-forming unit.
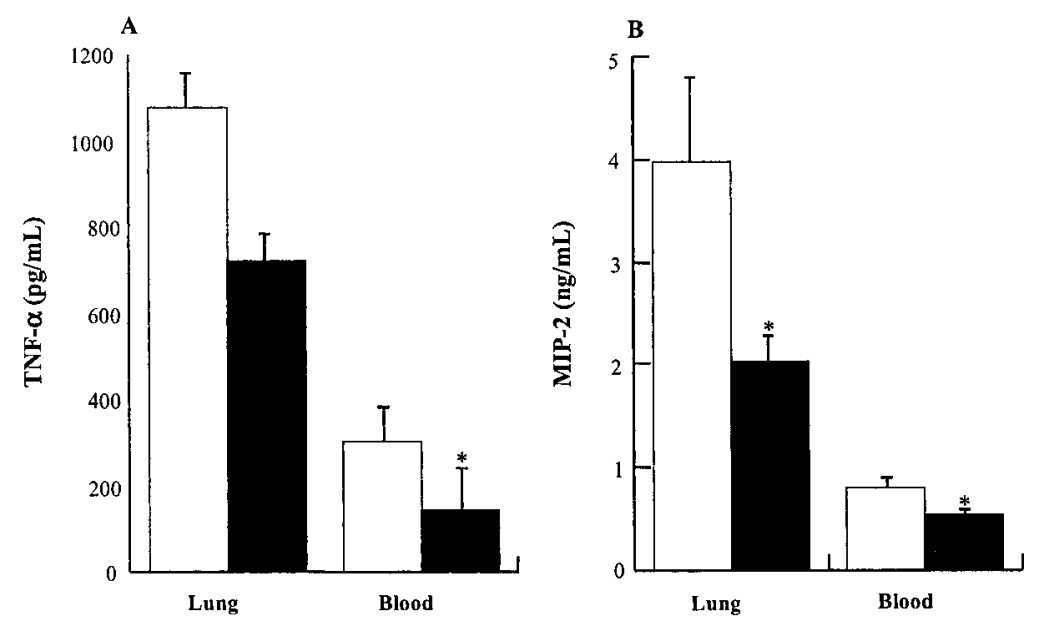

Figure 4. Concentrations of tumor necrosis factor $(T N F)-\alpha(A)$ and macrophage inflammatory protein $(M I P)-2(B)$ in lung homogenate and blood $48 \mathrm{hrs}$ after Pseudomonas aeruginosa intratracheal inoculation. Animals were ventilated with either tidal volume (VंT) $7 \mathrm{~mL} / \mathrm{kg}$ and positive end-expiratory pressure (PEEP) $5 \mathrm{~cm} \mathrm{H}_{2} \mathrm{O}$ (open bars, $\mathrm{n}=18$ ) or $21 \mathrm{~mL} / \mathrm{kg}$ with zero PEEP (filled bars, $\mathrm{n}=15$ ) under $\mathrm{FIO}_{2} 0.4$ for $1 \mathrm{hr}$ before bacterial challenge. ${ }^{*} p<.05$ vs. low VंT with PEEP group in the same specimens.

strategy for only $1 \mathrm{hr}$ before bacterial lung instillation can increase susceptibility to bacteremia as reflected by a higher frequency of positive bacterial cultures in blood. This may be associated with depression of host defense mechanisms as reflected by a subsequent lower cytokine response.

If anything, the animals treated with the protective strategy had higher mean arterial pressure; it is thus unlikely that this factor could explain our results. We did not do a power calculation. We thought that very large differences in blood pressure would be needed to (possibly) have an effect on host defense. We decided to prevent this problem by applying ventilatory strategies that had the same mean airway pressure, because this is a major determinant of hemodynamics (15), all else being equal. As a confirmation, we measured blood pressure in a few animals. These values remained in the normal range, and were certainly not lower in the injurious group, so we did not believe it was necessary to perform further studies to address this. However, there are several limitations in the present model including the limited ventilation period and lack of evaluation of different PEEP levels on the results.

\section{High $\dot{V}_{T}$ Ventilated Lung Becomes Vulnerable to Bacteremial Challenge}

A high $\dot{V}$ T of $21 \mathrm{~mL} / \mathrm{kg}$ was selected to ventilate the otherwise normal lungs of the healthy rats in the present study. This was to target a similar peak airway pressure (25 to $35 \mathrm{~cm} \mathrm{H}_{2} \mathrm{O}$ ), as seen in critically ill patients ventilated with a "conventional" mechanical ventilation. The regional lung distension produced by this VंT would be similar as would occur using a $\dot{V}$ T of $7 \mathrm{~mL} / \mathrm{kg}$ in patients with acute respiratory distress syndrome who have $2 / 3$ of their lungs not available for ventilation because of consolidation, fluid, etc (16). Our results are similar to those from studies in which bacterial challenge was followed by mechanical ventilation. In a dog model of Escherichia coliinduced pneumonia at $24 \mathrm{hrs}$, mechanical ventilation with a $\dot{V} \mathrm{~T}$ that was adjusted to reach a transpulmonary pressure of 35 $\mathrm{cm} \mathrm{H}_{2} \mathrm{O}$ resulted in an increased positive blood culture and lung injury reflected by histologic alterations (3). In another study using Klebsiella Pneumoniaeinduced pneumonia in rats, Verbrugge et al. (4) reported that mechanical ventilation with peak inspiratory pressures of 30 $\mathrm{cm} \mathrm{H}_{2} \mathrm{O}$ and zero PEEP for $3 \mathrm{hrs}$ led to the highest frequency of bacteremia among four different ventilatory strategies. A possible explanation for these studies is that an injurious ventilatory strategy induces lung microvascular injury resulting in pulmonary edema (6), which leads to a higher lymph flow accelerating bacterial translocation draining via the lymphatics into the blood circulation (17). Direct translocation of bacteria from lung into the circulation may also contribute to the development of bacteremia. Interestingly, using a model of mechanical ventilation before $P$. aeruginosa inoculation, we found similar results as in those studies mentioned above using pneumonia models followed by ventilation $(3,4,17)$. Our model included the use of relatively high airway pressures before bacterial instillation; thus, lymph flow would not be increased once the bacteria were inoculated. Thus, our data demonstrate that mechanical ventilation can cause otherwise healthy lungs to become vulnerable to bacterial challenge, contributing to bacteremia.

Our data demonstrate that rats ventilated with high VंT and zero PEEP had greater bacterial numbers in the systemic circulation than those ventilated with low 
$n$ injurious venti-

latory strategy

predisposes ani-

mals to subsequent bactere-

mia associated with an im-

paired host defense reflected

by cytokine response.

VंT and PEEP. We wanted to avoid the injury that might occur with atelectasis secondary to anesthesia in these animals. Thus, although there is little evidence to suggest that the lack of PEEP is a significant factor that causes injury in such a model, we thought that there would not be any great injury with this low level of PEEP. Thus, we opted to use it because we wanted to keep mean airway pressure similar in the two groups.

Several mechanisms may be responsible for the increased susceptibility to bacterial instillation observed in the high VंT group: First, surfactant is believed to have an important role in clearing bacteria such as $P$. aeruginosa $(18,19)$. We have previously shown that an injurious ventilatory strategy similar to the one used in the present study decreases lung compliance, and increases the amount of surfactant large aggregates and total lavage protein suggesting surfactant dysfunction $(20,21)$. A second possibility is that the injury to the epithelium of the lung may increase the likelihood of bacterial adherence to the airway (11). In addition, ventilation itself can result in a widespread destruction of epithelial cells leading to denudation of basement membranes and severe damage in the alveolarcapillary barrier (5-7). This barrier membrane destruction may result in bacterial translocation from the lung into the systemic circulation (22). The third possibility may be related to the effect of the high Vं strategy on development of lung injury-perhaps related to increased lung permeability $(23,24)$. For example, our results are in agreement with those reported by Johanson et al. (24) showing that preexisting lung injury induced by exposure to hyperoxia promoted $P$. aeruginosa translocation from the lung into the bloodstream in hamsters. Taken together, we think that the increased risk is likely related to the degree of overdistension with the large VT and to the recruitment/decruitment that occurs with zero PEEP.

\section{Cytokine Responses Were Depressed in High $\dot{V}_{T}$ Ventilated Rats in the Presence of Bacteria}

Bacteria or bacterial byproducts such as lipopolysaccharide are known to stimulate cytokine production by various cells or tissues (25). Several studies have also reported that injurious mechanical ventilation increases cytokine production by the lung $(8-10)$. One might then expect that the higher rate of positive bacterial culture or the increased bacterial number observed in the high VंT group would be associated with an increased cytokine production. Our results revealed the opposite: although a greater bacterial number was found, the blood TNF- $\alpha$ concentrations and MIP-2 concentrations, both in the lung and blood, were lower in the rats that were exposed to the high VंT ventilation than those who ventilated with low VंT strategy. Several mechanisms may be involved: first, the cytokine levels we measured were obtained $48 \mathrm{hrs}$ after mechanical ventilation. In all of the studies that we are familiar with, cytokine levels were measured much sooner after the injurious mechanical ventilation period $(3,4)$, so the results are not directly comparable. Second, less animals in the injurious group reached the 48-hr end point. To the extent that these animals would have had the highest cytokine concentrations, we would have an underestimate of cytokine levels because of this drop-out. Third, cytokine degradation is susceptible to proteases released from bacteria and injured cells. For example, both alkaline protease and elastase released from $P$. aeruginosa are able to degrade TNF- $\alpha$ and interferon- $\gamma$ (26). Moreover, van Kessel et al. (27) reported that TNF- $\alpha$ could be degraded by proteolytic enzymes released from activated neutrophils. Fourth, the injurious ventilatory strategy may have impaired the function of phagocytes such as alveolar macrophages (28), although this was not examined in the present study. Finally, the bacterial/cytokine interaction is a complex one with many caveats. Some investigators have demonstrated that systemic infection or bacteremia is enhanced by neutralization of interferon- $\gamma$ or TNF- $\alpha$ in mice (29), suggesting that these cytokines may have direct or indirect antimicrobial effects. However, other researchers have reported increased growth of bacteria by cytokines in ex vivo studies $(30,31)$. It seems that this may be attributable to a U-shaped dose-response curve, with the specific response (decreased or increased growth) dependent on the location in the dose-response curve. Our results are in agreement with the data reported in in vivo mice models (29) reflecting an overall systemic response to bacteria and bacterial products.

Our results have potential clinical implications if these results can be extrapolated to humans. They would suggest one mechanism for the high frequency of ventilator-associated pneumonia in ventilated patients and would also suggest that the use of a protective ventilatory strategy could potentially mitigate this complication of ventilation, and could decrease the prevalence of septicemia, and possibly death.

In conclusion, the use of an injurious ventilatory strategy may lead to altered host defense, manifest by an increased predisposition to subsequent bacteremia. Whether this increased bacteremia is caused by, or leads to, decreased cytokines is as yet undetermined.

\section{ACKNOWLEDGMENTS}

We are grateful to Dr. Brendan Mullen, Department of Pathology, Mount Sinai Hospital, University of Toronto, for performing lung pathologic examinations.

\section{REFERENCES}

1. Leu HS, Kaiser DL, Mori M, et al: Hospitalacquired pneumonia: Attributable mortality and morbidity. Am J Epidemiol 1989; 1258-1267

2. Bauer TT, Ferrer R, Angrill J, et al: Ventilator-associated pneumonia: Incidence, risk factors, and microbiology. Semin Respir Infect 2000; 15:272-279

3. Nahum A, Hoyt J, Schmitz L, et al: Effect of mechanical ventilation strategy on dissemination of intratracheally instilled Escherichia coli in dogs. Crit Care Med 1997; 25: 1733-1743

4. Verbrugge SJC, Šorm V, van't Veen A, et al: Lung overinflation without positive endexpiratory pressure promotes bacteremia after Klebsiella pneumoniae. Intensive Care Med 1998; 24:172-177

5. Dreyfuss D, Basset G, Solar P, et al: Intermittent positive-pressure hyperventilation with high inflation pressures produces pulmonary 
microvascular injury in rats. Am Rev Respir Dis $1985 ; 132: 880-884$

6. Dreyfuss D, Soler P, Saumon G: Mechanical ventilation-induced pulmonary edema. Interaction with previous lung alterations. Am J Respir Crit Care Med 1995; 151: 1568-1575

7. Tsuno K, Prato P, Kolobow T: Acute lung injury from mechanical ventilation at moderately high airway pressures. J Appl Physiol 1990; 69:956-961

8. Tremblay L, Valenza F, Ribeiro SP, et al: Injurious ventilatory strategies increase $c y$ tokines and c-fos m-RNA expression in an isolated rat lung model. J Clin Invest 1996; 99:944-952

9. Chiumello D, Pristine G, Slutsky AS: Mechanical ventilation affects local and systemic cytokines in an animal model of acute respiratory distress syndrome. Am J Respir Crit Care Med 1999; 160:109-116

10. von Bethmann AN, Brasch F, Nusing R, et al: Hyperinflation induces release of cytokines from perfused mouse lung. Am J Respir Crit Care Med 1998; 157:263-272

11. Chen GH, Reddy RC, Newstead MW, et al: Intrapulmonary TNF gene therapy reverses sepsis-induced suppression of lung antibacterial host defense. J Immunol 2000; 165: 6496-6503

12. Miyazaki Y, Araki K, Vesin C, et al: Expression of a tumor necrosis factor-alpha transgene in murine lung causes lymphocytic and fibrosing alveolitis. A mouse model of progressive fibrosis. J Clin Invest 1995; 96:250-259

13. Ventilation with lower tidal volumes as compared with traditional tidal volumes for acute lung injury and the acute respiratory distress syndrome. The Acute Respiratory Distress
Syndrome Network. N Engl J Med 2000; 342 : 1301-1308

14. Savel RH, Yao EC, Gropper MA: Protective effects of low tidal volume ventilation in a rabbit model of Pseudomonas aeruginosainduced lung injury. Crit Care Med 2001; 29:392-398

15. Marini JJ, Ravenscraft SA: Mean airway pressure: Physiological determinants and clinical importance. Part 2. Clinical implications. Crit Care Med 1992; 20:1604-1616

16. Goodman LR, Fumagalli R, Tagliabue P, et al: Adult respiratory distress syndrome due to pulmonary and extrapulmonary causes: $\mathrm{CT}$, clinical, and functional correlations. $\mathrm{Ra}$ diology 1999; 213:545-552

17. Brigham KL: Mechanisms of lung injury. Clin Chest Med 1982; 3:9-24

18. LeVine AM, Whitsett JA: Pulmonary collectins and innate host defense of lung. Microbes Infect 2001; 2:161-166

19. Ofek I, Mesika A, Kalina M, et al: Surfactant protein D enhances phagocytosis and killing of unencapsulated phase variants of Klebsiella pneumoniae. Infect Immun 2001; 69:24-33

20. Veldhuizen RA, Tremblay LN, Govindarajan A, et al: Pulmonary surfactant is altered during mechanical ventilation of isolated rat lung. Crit Care Med 2000; 28:2545-2551

21. Wyszogrodski I, Kyei-Aboagye K, Taeusch HW: Surfactant inactivation by hyperventilation: Conservation by end-expiratory pressure. J Appl Physiol 1975; 38:461-466

22. Reynolds HY: Bacterial adherence to respiratory tract mucosa: A dynamic interaction leading to colonization. Semin Respir Infect 1987; $2: 8-19$

23. Mucsedere JG, Mullen JB, Slutsky AS: Tidal ventilation at low airway pressures can aug- ment lung injury. Am J Respir Crit Care Med 1994; 149:1327-1334

24. Johanson WG, Highchi JH, Woods DE, et al: Dissemination of Pseudomonas aeruginosa during lung infection in hamsters. Am Rev Respir Dis 1985; 132:358-361

25. Ghofrani HA, Rosseau S, Walmrath D, et al: Compartmentalized lung cytokine release in response to intravascular and alveolar endotoxin challenge. Am J Physiol 1996; 270 : L62-68

26. Parmely M, Gale A, Clabaugh M, et al: Proteolytic inactivation of cytokines by Pseudomonas aeruginosa. Infect Immun 1990; 58 : 3009-3014

27. van Kessel KP, van Strijp JA, Verhoef J: Inactivation of recombinant human tumor necrosis factor-alpha by proteolytic enzymes released from stimulated human neutrophils. J Immunol 1991; 147:3862-3868

28. Pugin J, Dunn I, Jolliet P, et al: Activation of human macrophages by mechanical ventilation in vitro. Am J Physiol 1998; 275: L1040-1050

29. Gulig PA, Doyle TJ, Clare-Salzler MJ, et al: Systemic infection of mice by wild-type but not Spv-Salmonella typhimurium is enhanced by neutralization of gamma interferon and tumor necrosis factor alpha. Infect Immun 1997; 65:5191-5197

30. Meduri GU, Kanangat S, Stefan J, et al: Cytokines IL-1beta, IL-6, and TNF-alpha enhance in vitro growth of bacteria. Am J Respir Crit Care Med 1999; 160:961-967

31. Kanangat S, Meduri GU, Tolley EA, et al: Effects of cytokines and endotoxin on the intracellular growth of bacteria. Infect Immun 1999; 67:2834-2840 